\title{
Research on Depression Literacy, Perceived Stigma and Help-Seeking Intentions of Teenagers from First and Second Tiered Cities in China
}

\author{
Hui Zhu \\ Tianjin Foreign Languages School, Tianjin, China \\ Email: cis2018@foxmail.com
}

How to cite this paper: Zhu, H. (2020). Research on Depression Literacy, Perceived Stigma and Help-Seeking Intentions of Teenagers from First and Second Tiered Cities in China. Psychology, 11, 1153-1169. https://doi.org/10.4236/psych.2020.118076

Received: June 8, 2020

Accepted: August 16, 2020

Published: August 19, 2020

Copyright $\odot 2020$ by author(s) and Scientific Research Publishing Inc. This work is licensed under the Creative Commons Attribution-NonCommercial International License (CC BY-NC 4.0). http://creativecommons.org/licenses/by-nc/4.0/ (c) (i) (8) Open Access

\begin{abstract}
[Objective] To understand teenagers' depression literacy, perceived stigma and intention to seek for help if suffering from depression, to explore the relationship among the three variables and the factors that influence these variables, to provide scientific evidence for further education on mental health for teenagers, reduction of stigma, and raising teenagers' intention to seek for professional help. [Methods] By convenient sampling, 77 teenagers from first and second tiered cities in China were selected through on the website Wenjuanxing. Depression Stigma Scale (DSS), Adolescent Depression Knowledge Questionnaire, and self-designed questionnaires on intentions to seek for help and on general information were used to measure the sample's perceived stigma, depression literacy, intentions to seek for help and general information respectively. [Results] The sample's average score of depression literacy was 10.86. Age and experiences of depression had influence on depression literacy. Information sources for depression knowledge were mainly the internet $(72.6 \%)$ and peers $(64.5 \%)$. The sample's average score of perceived stigma was 23.8 , higher than the mid score 21 , indicating a slightly lower perceived stigma. There was a negative correlation between perceived stigma and depression literacy $(\mathrm{r}=0.338, p<0.01) .72(93.5 \%)$ of the sample claimed that they will seek for professional help if they find themselves suffering from depression. The main recourse to help was professionals (61.1\%). The possible obstacle for help seeking was mainly stigma factor. Perceived stigma was showed to have an effect on intention to seek for help $(\mathrm{p}=0.003<0.01)$. [Conclusion] Teenagers aged 15 - 19 who reported to have similar symptom of depression had higher score in depression literacy. Perceived stigma and depression literacy are negatively correlated. Perceived stigma had influence on intention to seek for help.
\end{abstract}


Keywords

Depression, Teenager, Stigma, Help-Seeking Intentions, Attitude, Mental Health, Community

\section{Introduction}

\subsection{Background}

According to Depression and Other Common Mental Disorders (WHO, 2017), $16 \%$ of the disease and injury in $10-19$-year-old teenagers is caused by mental health issues. Half of all sufferers of mental health problems start by the age of 14 , but most did not detect the condition or receive proper treatment. Nowadays in China, the depressed teenagers suffer not only from the disease, but also from the lack of relative knowledge and stigma of depression, which are associated with low intention to seek for professional help. The lack of professional treatment often leads to the deterioration of the sufferers' mental state, some cases ending up with suicides or self-mutilation. Therefore, this study aims to detect and analyze the factors that prevent teenagers from seeking for help if they suffer from depression. In doing so, we hope to find possible means to encourage teenagers to seek for professional help when they suffer from depression.

\subsection{Literature Review}

\subsubsection{Depression}

Depression is a persistent emotional state involvingdepressed mood, sadness, low spirits, disappointment and displeasure. Physiologically, adolescent depression is mainly characterized by drinking and eating disorder, sleeplessness, tiredness, and cry without reason (Ye, 2008); and psychologically, it is characterized by guilt, self-accusation, negativity, pessimism, loss of interest, etc. Depression can prevent adolescent sufferers from learning, living and interacting with others normally, and thus it has a great influence on the sufferers and their families. Besides, teenagers often fail to receive treatment in time due to the lack of relevant knowledge and stigma of themselves and their parents, limited relevant medical services and their disapproval of treatment method dominated by medication (Ma, 2016).

\subsubsection{Stigma}

Stigma, referring to an inner shame experiences resulting from suffering from an illness, reflects a psychological stress response of the sufferers (Liu, Sun, Sun, \& Chang, 2013). Depression stigma can be divided into self-stigma, personal stigma and perceived stigma. Self-depression stigma refers to a person's own response to depression and help seeking; personal depression stigma usually refers to a person's personal thoughts of and attitudes towards depression; and perceived stigma of depression refers to a person's perception of other people's thoughts and feelings about depression (Xu et al., 2014). This paper agrees to 
this classification method and considering the sensitivity of teenagers to self-evaluation, it will mainly explore teenagers' perceived stigma.

Stigma affects the sufferers in multiple ways. It can reduce the intentions of sufferers from mental disease to seek help (Wahl, 1999), reduce their self-confidence and greatly affects their life quality; and it usually makes the sufferers keep their disease secret, which will strengthen their anxiety and fear (Jorm \& Wright, 2008). As a result, the sufferers cannot seek timely help, which will prevent them from recovering.

\subsubsection{Factors Affecting Stigma}

Scholars have not reached a unified conclusion in their studies on depression stigma's correlation with some demographic factors, such as gender (Zhou et al. 2019) (Guo \& Zhang, 2008) and age (Sun, 2013) (Guo \& Zhang, 2008). However, most scholars have agreed that divorced people, people living alone, people with a relatively low educational level and people without local registered permanent residence have a higher perceived stigma (Luo, 2012).

According to many studies, the mental health knowledge level has a significant effect on depression stigma and they are negatively correlated. People with a higher mental health knowledge level had a lower stigma (Luo, 2012).

The depression level and psychological stress have a significant effect on teenagers' intention to seek help. The greater the psychological stress of teenagers was, the less willing they were to seek help ( $\mathrm{Su}, 2015)$. In Liuyang City, the more depressed residents were, the less likely they were to seek help (Luo, 2012). At the same time, experiences of depression or contact with depression sufferers had an impact on the depression stigma of teenagers, and that there was a difference in the impact of their own suffering and contact with depression sufferers on the stigma (Jorm \& Wright, 2008). There was also a significant correlation between parents' stigma and teenagers' stigma, so it is necessary to strengthen the publicity and education for parents (Jorm \& Wright, 2008).

\subsubsection{Teenagers' Intentions to Seek Help}

As mentioned above, stigma usually makes the sufferers keep their disease secret, and reduces the intentions of sufferers to seek help, as a result of which, the sufferers cannot seek timely help. Junior high school students usually seek help from their classmates, parents, and teachers (Su, 2015).

\subsection{Research Objectives}

As shown in previous studies, people's level of mental health literacy has significant influence on stigma of mental diseases, which influences their willingness to seek for professional help. However, mental health knowledge encompasses a broad range of mental diseases, some of which are only remotely related with depression. So far, few studies have been done to investigate teenagers' depression literacy in China. Hence, in this study, we would like to explore the relationship between teenagers' depression literacy and the perceived stigma of de- 
pression, as well as whether stigma reduces teenagers' willingness to seek for professional help.

\section{Materials and Methods}

\subsection{Research Subjects}

77 teenagers (junior and senior high school students) from first and second tiered cities in China participated in the study through voluntary response to our questionnaire. Among these participants, 30 are male and 47 are female; 15 are from middle school and 62 are from high school. All participants are from first and second tiered cities in China. A large portion of participants are from Tianjin (37 participants), and others scatter in large cities in Hebei, Sichuan, Jiangsu, Fujian, Inner Mongolia, etc. Among the 77 participants, 12 claimed to have experienced depression-like symptoms and have received professional help (15.6\%) and 25 claimed to have family members experiencing depression-like symptoms.

\subsection{Research Tools}

\subsubsection{Depression Stigma Scale (DSS)}

Depression Stigma Scale used in this study includes 7 items. Each item is an attitude question whose response includes 5 choices from "strongly disagree" (1 point) to "strongly agree" (5 points). The revised Chinese version of Depression Stigma Scale was verified by Liu Baohua et al among the young people aged 15 24 in Beijing, and its coefficient of internal consistency (Cronbach's $\alpha$ ) was 0.67, indicating medium reliability, so this scale can be applied to the Chinese young people (Liu et al., 2013). According to a survey on stigma of Australian teenagers by Jorm et al., the 2 items irrelevant to teenagers' life in the Scale are removed and the other 7 items are retained (Jorm \& Wright, 2008). According to reliability test, its reliability is good (Cronbach's $\alpha=0.74$ ), so similar revision can be applied to the Chinese teenagers.

\subsubsection{Depression Literacy}

Since there is no questionnaire to effectively measure the teenagers' depression knowledge level in Chinese, this paper adopts the translated Adolescent Depression Knowledge Questionnaire (ADKQ). There are 15 items in the questionnaire, including 13 true or false questions, 1 point for a correct answer, no score for wrong answers; and 2 gap-filling questions, 5 points and 2 points for answers meeting the requirements, respectively. The questionnaire was applied among American young people, and the Kuder-Richardson reliability coefficient was 0.89 , indicating good reliability (Hart et al., 2014).

\subsubsection{Factors Affecting Stigma}

This paper adopts the self-designed questionnaire on depression-related experiences to learn the channels through which the teenagers know the depression and related information. Depression-related experience was investigated by ask- 
ing whether the participants had experienced depression-like symptoms and whether the participants received professional help. The source of depression-related information was designed as a multiple choice question in which common sources of information such as internet, school, professionals, and family were provided as choices and participants could respond by selecting multiple sources. This paper also used a self-designed questionnaire on personal information to learn the sample's age and gender.

\subsubsection{Intentions to Seek Help}

This paper adopts the self-designed questionnaire on intentions to seek for help to know the sample's intentions to seek for help, recourse to help and possible obstacle for help seeking. Intention to seek for help was asked in a yes or no question. Resources to help were given as options and participants could select one that best matches their intention. Possible obstacles for help seeking were provided as options, which also include "no obstacle", and participants could select one that best describes their situation.

\subsection{Research Methods}

\subsubsection{Questionnaire Collection}

The questionnaires were published on Wenjuanxing, an online platform for survey, assessment, and opinion poll. Researchers could upload their questionnaires to Wenjuanxing and people could get access and respond to the questionnaire by clicking the link to the questionnaire. Of the 101 participants that volunteered to fill out the questionnaire, 77 were teenagers in China's first and second tiered cities.

\subsubsection{Data Analysis Methods}

Statistical analysis was carried out using SPSS 24.0.

1) Descriptive analysis

The mean and standard deviation of general socio-demographic characteristics, stigma, depression-related experiences, self-assessment information awareness, information source and depression knowledge level of the sample were used for statistical description.

2) Single-factor analysis

The one-sample $t$ test was used to compare the average score of the scale with the mid score " 3 " in the scale, so as to judge the severity of stigma. The two independent sample t-test was used to analyze whether there were differences in stigma and depression knowledge level among teenagers with different medical histories. The two-sided chi-square test was used to analyze whether there were differences in help-seeking intentions and possible obstacle for help seeking among teenagers with different demographic characteristics and information sources, and whether the differences were significant.

3) Multiple-factor analysis

The personal depression-related experiences, depression-related experiences of family members, gender, age, and depression literacy were set as independent 
variables, while stigma was set as dependent variable. The multi-factor analysis of variance was introduced to analyze the influence of various factors on stigma. Based on the logistic regression model, independent variables were selected by backward stepwise likelihood ratio method, and a model was built to explore the influence of various factors on the help-seeking intentions.

4) Correlation analysis

The Pearson correlation analysis was used to analyze the relationship between the total score of Depression Knowledge Questionnaire and that of Depression Stigma Scale.

\section{Results}

\subsection{Basic Information of the Sample}

Of the 77 teenagers who participated in the survey, 30 were males (39\%) and 47 were females (61\%). 15 of them are aged $13-15(19.5 \%)$, while 62 of them are aged 16 - 19 (80.5\%) (See Table 1).

\subsection{Depression Literacy}

\subsubsection{Related Experience of Depression}

Of the 77 teenagers, $45(58.4 \%)$ said they had experienced depression-like symptoms, with 12 receiving professional help and 33 not, and 32 (41.6\%) said they had not experienced depression-like symptoms. 41 (53.2\%) said their family members had experienced depression-like symptoms, with 25 receiving professional help and 14 not; 32 (41.6\%) said their family members had not experienced depression-like symptoms (See Table 2).

Table 1. Gender and age of the participants.

\begin{tabular}{cccc}
\hline Variable & Group & Number & Constituent ratio \\
\hline Gender & Male & 30 & $39 \%$ \\
& Female & 47 & $61 \%$ \\
Age & $13-15$ & 15 & $19.5 \%$ \\
& $16-19$ & 62 & $80.5 \%$ \\
\hline
\end{tabular}

Table 2. Participants' related experiences of depression.

\begin{tabular}{|c|c|c|c|}
\hline Variable & Group & Number & Constituent ratio \\
\hline \multirow{3}{*}{$\begin{array}{c}\text { Participants' related } \\
\text { experiences }\end{array}$} & Yes and received help & 12 & $15.6 \%$ \\
\hline & Yes and did not receive help & 33 & $42.9 \%$ \\
\hline & No & 32 & $41.5 \%$ \\
\hline \multirow[t]{3}{*}{$\begin{array}{c}\text { Family's related } \\
\text { experiences }\end{array}$} & Yes and received help & 25 & $32.5 \%$ \\
\hline & Yes and did not receive help & 14 & $18.2 \%$ \\
\hline & No & 38 & $49.3 \%$ \\
\hline
\end{tabular}




\subsubsection{Depression Literacy}

\section{1) Accuracy of items on depression knowledge questionnaire}

77 teenagers completed the Depression Knowledge Questionnaire, and for 13 true or false questions, the number of correct answers and accuracy of each item was calculated and the items were ranked based on the accuracy. The top three items are "A behavior change is a symptom of depression", " $5 \%$ teenagers suffer from major depression" and "The causes of major depression are well learned", with the accuracy of $92.2 \%, 88.3 \%$ and $84.4 \%$, respectively. The last three items are "People who experiences major stressors, such as parents' divorce, always suffer from depression", "Bipolar affective disorder is more common than major depression" and "Major depression is a treatable disease", with the accuracy of $49.4 \%, 37.7 \%$ and $36.4 \%$, respectively (See Table 3 ).

The two gap-filling questions are "Please list 5 symptoms of depression" and "Please list two symptoms of mania" with total score of 5 points and 2 points, respectively; their average scores are 1.53 points and 0.48 points, respectively.

\section{2) Depression literacy}

77 teenagers completed the Depression Knowledge Questionnaire, and the score of 15 items, including true or false questions and gap-filling questions, were added to obtain the final score of the individual sample, with a minimum score of 0 and a full score of 20 points. By calculating the score of each individual sample, the average score of the sample was obtained, 10.86 points. By comparing this score with the average score (12.58) obtained by Swartz et al. (2007) who used ADKQ questionnaire to survey the general American teenagers, and using the one-sample $t$ test, it can be seen that the average score of the sample was significantly lower than the average score of the American teenagers studied by Swartz et al. (2007) (See Table 4, Figure 1).

Table 3. Adolescent depression knowledge questionnaire items and accuracy rate.

\begin{tabular}{ccc}
\hline ADKQ Items & Correct Answer & Accuracy \\
\hline A behavior change is a symptom of depression. & 71 & $92.2 \%$ \\
$5 \%$ teenagers suffer from major depression. & 68 & $88.3 \%$ \\
The causes of major depression are well learned. & 65 & $84.4 \%$ \\
Drug abuse and excessive drinking can & 64 & $83.1 \%$ \\
be a symptom of depression. & 59 & $76.6 \%$ \\
Some people are immune to depression & 58 & $75.3 \%$ \\
Depression sufferers always feel sad. & 57 & $74.0 \%$ \\
Major depression is part of adolescence. & 55 & $71.4 \%$ \\
Depression can be controlled by willpower. & 47 & $61.0 \%$ \\
Major depression is a treatable medical condition. & 42 & $54.5 \%$ \\
Depression can run in families & 38 & $49.4 \%$ \\
People who experiences major stressors, & & $37.7 \%$
\end{tabular}




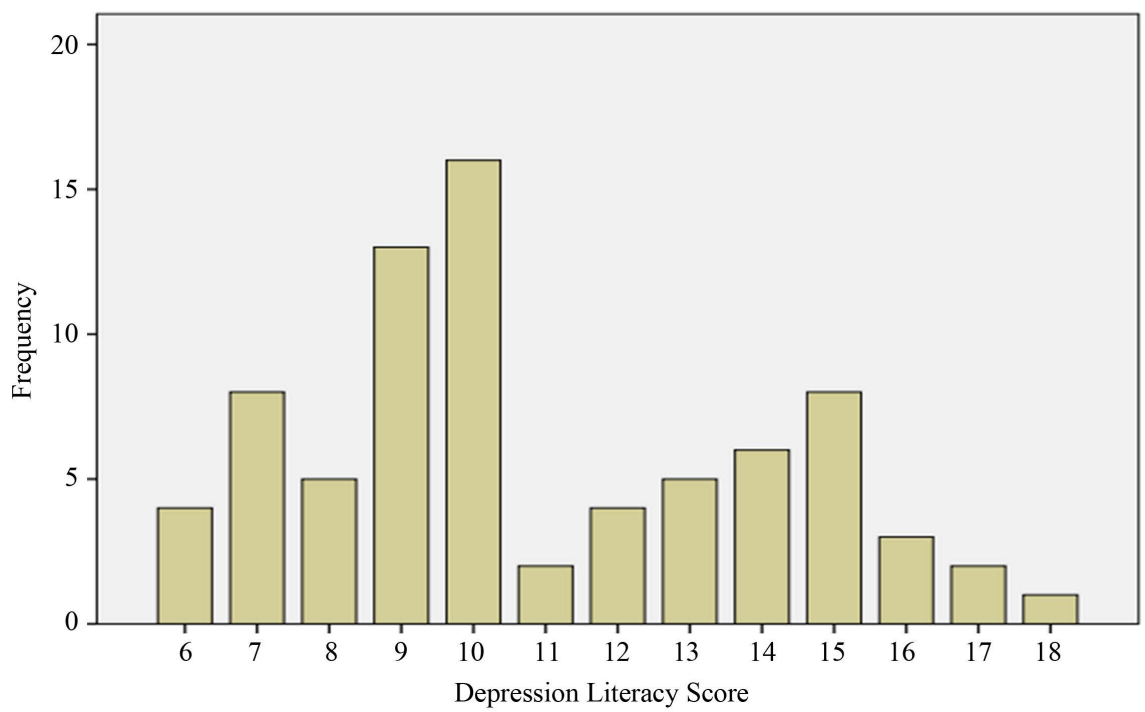

Figure 1. Distribution of depression literacy score.

Table 4. One-sample test of depression literacy (Test value $=12.58)$.

\begin{tabular}{|c|c|c|c|c|c|c|}
\hline & \multirow[t]{2}{*}{$\mathrm{t}$} & \multirow[t]{2}{*}{$\mathrm{df}$} & \multirow{2}{*}{$\begin{array}{c}\text { Sig. } \\
\text { (2-tailed) }\end{array}$} & \multirow{2}{*}{$\begin{array}{c}\text { Mean } \\
\text { difference }\end{array}$} & \multicolumn{2}{|c|}{$\begin{array}{l}\text { 95\% Confidence Interval } \\
\text { of the Difference }\end{array}$} \\
\hline & & & & & Lower & Upper \\
\hline Depression Knowledge & -4.840 & 76 & 0.000 & -1.723 & -2.43 & -1.01 \\
\hline
\end{tabular}

\subsubsection{Information Sources}

Of the 77 teenagers participating in the survey, 62 said they had heard of depression-like symptoms, while 15 said they had never. For teenagers who had heard of depression, the Internet was the main information source (72.6\%), followed by peers $(64.5 \%)$, schools $(29.0 \%)$, parents $(24.4 \%)$, relevant professionals $(22.6 \%)$ and others (8.1\%).

\subsection{Stigma}

The mean of stigma of 77 teenagers was 23.8 , slightly higher than the mid score (21 points), and the standard deviation was 4.98 . Through the one-sample $t$ test, it could be seen that the average score of stigma of the sample was higher than the mid score $(p<0.01)$, and lower than 28 points which indicates low stigma ( $p$ $<0.01$ ) (See Table 5, Figure 2).

\subsection{Intentions to Seek Help}

Of the 77 teenagers participating in the survey, 72 (93.5\%) said they would seek help/encourage others to seek help if they or their friend showed symptoms of depression, while 5 (6.5\%) said they would not. Of the teenagers who would seek help, $44(61.1 \%)$ said they would seek help from a mental health or medical professional/counselor; 17 (23.6\%) would seek help from classmates/peers, 7 (9.7\%) would seek help from family members, 3 (4.2\%) would seek help from teachers/school doctors/other school staff, and 1 would seek help from other groups. 


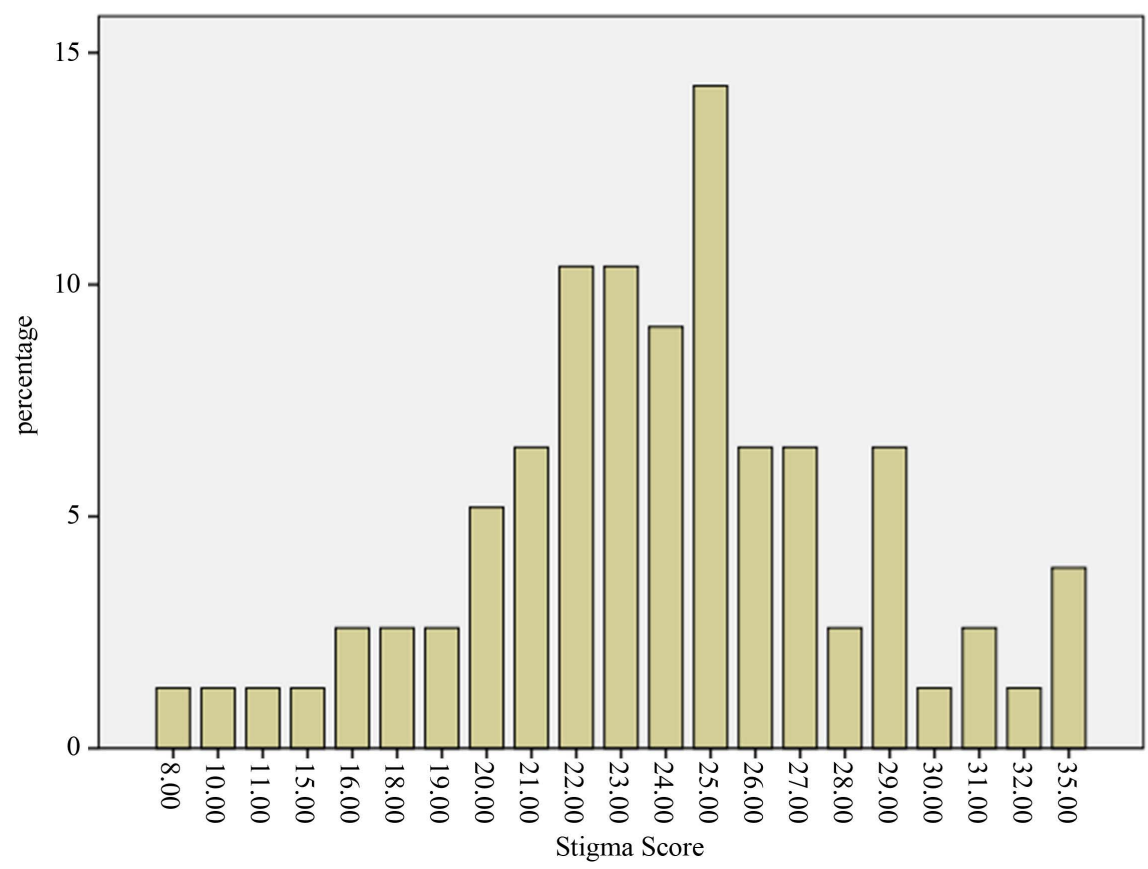

Figure 2. Distribution of stigma scores.

Table 5. One-sample test of stigma.

\begin{tabular}{|c|c|c|c|c|c|c|}
\hline \multirow{2}{*}{ Total Score of Stigma } & \multirow[t]{2}{*}{$\mathrm{t}$} & \multirow{2}{*}{ df } & \multirow{2}{*}{$\begin{array}{c}\text { Sig. } \\
\text { (2-tailed) }\end{array}$} & \multirow{2}{*}{$\begin{array}{c}\text { Mean } \\
\text { difference }\end{array}$} & \multicolumn{2}{|c|}{$\begin{array}{c}\text { 95\%Confidence Interval } \\
\text { of the Difference }\end{array}$} \\
\hline & & & & & Lower & Upper \\
\hline Test Value $=21$ & 4.933 & 76 & 0.000 & 2.80519 & 1.6727 & 3.9377 \\
\hline Test Value $=28$ & -7.377 & 76 & 0.000 & -4.19481 & -5.3273 & -3.0623 \\
\hline
\end{tabular}

Among the possible obstacles for help seeking, stigma accounted for $57.1 \%$, Depression Literacy accounted for $16.9 \%$, social resources accounted for $15.6 \%$, and no obstacle accounted for $10.4 \%$ (See Table 6).

\subsection{Analysis on Factors Affecting Depression Literacy}

\subsubsection{Demographic Factors}

Of the 77 teenagers, 30 were males and 47 were females, with an average score of 10.91 points and 10.55 points, respectively. Through the one-way ANOVA, teenagers of different genders had no significant difference in depression literacy ( $F$ $=0.126, p>0.05$ ). There were 15 people aged below 15 and 62 aged $15-19$, with an average score of 9.77 points and 11.55 points, respectively. Through the one-way ANOVA, there is a significant difference in depression literacy $(\mathrm{F}=$ 6.418, $p<0.05$ ) between teenagers of different age groups, and the teenagers aged 15 - 19 had a higher depression literacy (See Table 7).

\subsubsection{Depression-Related Experience}

Of the 77 teenagers, 45 said they had experienced depression-like symptoms, and $32(41.6 \%)$ said they had not experienced depression-like symptoms, with 
Table 6. Obstacles for help seeking and their constituent ratio.

\begin{tabular}{|c|c|c|c|c|}
\hline $\begin{array}{l}\text { Obstacles for } \\
\text { help seeking }\end{array}$ & Specific Items & Number & $\begin{array}{l}\text { Constituent } \\
\text { ratio }\end{array}$ & $\begin{array}{c}\text { Constituent ratio } \\
\text { of this factor }\end{array}$ \\
\hline \multirow{3}{*}{ Stigma } & $\begin{array}{l}\text { I'm afraid of being } \\
\text { talked about/laughed at }\end{array}$ & 13 & $16.9 \%$ & \multirow[b]{3}{*}{$57.1 \%$} \\
\hline & It's difficult to talk about it & 14 & $18.2 \%$ & \\
\hline & $\begin{array}{l}\text { It can be embarrassing, } \\
\text { and I think that this } \\
\text { doesn't happen to everyone }\end{array}$ & 17 & $22.1 \%$ & \\
\hline \multirow{2}{*}{$\begin{array}{l}\text { Depression } \\
\text { Literacy }\end{array}$} & $\begin{array}{l}\text { Treatment may not } \\
\text { work/medication } \\
\text { may have side effects }\end{array}$ & 5 & $6.5 \%$ & \\
\hline & $\begin{array}{l}\text { I needn't help and } \\
\text { can solve it myself. }\end{array}$ & 8 & $10.4 \%$ & $16.9 \%$ \\
\hline Social resources & $\begin{array}{l}\text { I can't find anyone for } \\
\text { help/don't know } \\
\text { where to go for help }\end{array}$ & 12 & $15.6 \%$ & $15.6 \%$ \\
\hline No obstacle & $\begin{array}{l}\text { Nothing can stop me } \\
\text { from seeking help. }\end{array}$ & 8 & $10.4 \%$ & $10.4 \%$ \\
\hline
\end{tabular}

Table 7. One-way ANOVA of demographic factors.

\begin{tabular}{ccccccc}
\hline & & Sum of Squares & $\mathrm{df}$ & Mean Square & $\mathrm{F}$ & Sig. \\
\hline \multirow{4}{*}{ Gender } & Intra-group & 1.247 & 1 & 1.247 & & \\
& Between-group & 740.182 & 75 & 9.869 & 0.126 & 0.723 \\
& Total & 741.429 & 76 & & & \\
& Intra-group & 22.694 & 58.445 & 1 & & \\
\multirow{3}{*}{ Age } & Between-group & 718.734 & 682.984 & 75 & 6.418 & 0.013 \\
& Total & 741.429 & 741.429 & 76 & & \\
\hline
\end{tabular}

an average score of 11.69 points and 9.69 points, respectively. Through the one-way ANOVA, there is a significant difference in scores between the two groups $(\mathrm{F}=8.429, p<0.01)$. Teenagers who said they had experienced depression-like symptoms had higher depression literacy.41 said their family members had experienced depression-like symptoms, and 36 said their family members had not experienced depression-like symptoms, with an average score of 11.37 points and 10.28 points, respectively. Through the one-way ANOVA, there is no significant difference in scores between the two groups $(\mathrm{F}=2.368, p>0.05)$ (See Table 8).

\subsubsection{Information Sources}

Of the 77 teenagers, 62 said they had heard of depression-like symptoms. Among them, 45 obtained related information from sources including the Internet and 17 obtained related information from sources excluding the Internet. Through the independent sample $t$ test, the average score of depression literacy 
Table 8. One-way ANOVA of depression-related experience.

\begin{tabular}{ccccccc}
\hline & & Sum of Squares & df & Mean Square & F & Sig. \\
\hline & Intra-group & 74.909 & 1 & 74.909 & & \\
$\begin{array}{c}\text { Personal } \\
\text { experiences }\end{array}$ & Between-group & 666.519 & 75 & 8.887 & 8.429 & 0.005 \\
& Total & 741.429 & 76 & & & \\
& Intra-group & 22.694 & 1 & 22.694 & & \\
$\begin{array}{c}\text { experiences } \\
\text { of Family }\end{array}$ & Between-group & 718.734 & 75 & 9.583 & 2.368 & 0.128 \\
Members & Total & 741.429 & 76 & & & \\
\hline
\end{tabular}

was compared between the two groups, and there is no significant difference between them $(p>0.05)$.

\subsection{Analysis on Factors Affecting Perceived Stigma}

\subsubsection{Demographic Factors}

Of the 77 teenagers, there were 30 males and 47 females, accounting for $39.0 \%$ and $61.0 \%$, respectively. The average score of male stigma was 22.9 points, while that of female stigma was 24.4 points. Independent sample $t$ test was used to analyze whether there is a significant difference in stigma scores between males and females. Through the test, there was no statistic difference between the two groups $(p>0.05)$.

Of the 77 teenagers, 15 were aged below 15 and 62 were aged $15-19$, accounting for $19.5 \%$ and $80.5 \%$ respectively. Both the average scores of the two groups were 23.8 points. Independent sample $t$ test was used to analyze whether there is a significant difference in stigma scores between the group aged below 15 and the one aged $15-19$. Through the test, there was no statistic difference between the two groups $(p>0.05)$.

\subsubsection{Depression-Related Experience}

Of the 77 teenagers, 45 said they had experienced depression-like symptoms, and $32(41.6 \%)$ said they had not experienced depression-like symptoms, accounting for $58.4 \%$ and $41.6 \%$, respectively. The average score of the teenagers who said they had experienced depression-like symptoms was 24.60 points, while that of the teenagers who said they had not experienced depression-like symptoms was 22.69 points. Independent sample $t$ test was used to analyze whether there is a significant difference between them. Through the test, there was no statistic difference between the two groups $(p=0.098>0.05)$.

Of the 77 teenagers, 41 said their family members had experienced depression-like symptoms, and 36 said their family members had not experienced depression-like symptoms, accounting for $53.2 \%$ and $46.8 \%$, respectively. The average score of the teenagers who said their family members had experienced depression-like symptoms was 23.5 points, while that of the teenagers who said their family members had not experienced depression-like symptoms was 24.8 points. Independent sample $t$ test was used to analyze whether there is a signifi- 
cant difference between them. Through the test, there was no statistic difference between the two groups $(p>0.05)$.

\subsubsection{Depression Literacy}

Pearson correlation analysis was used to analyze the correlation between depression literacy and perceived stigma of teenagers. According to the analysis, there was a correlation between the two, and the results were statistically significant ( $\mathrm{r}$ $=0.338, p<0.01)$ (See Table 9).

\subsection{Factors Affecting Intentions to Seek Help}

\subsubsection{Multivariate Logistic Regression Analysis on Intentions to Seek Help}

The age, gender, depression-related experiences and depression literacy were set as independent variables, while intentions to seek help were set as dependent variable. The logistic stepwise regression model was introduced, and forward conditional screening in the analysis method was used to select the influencing factors $\left(\mathrm{a}_{\mathrm{in}}=0.05, \mathrm{a}_{\text {out }}=0.10\right)$. As a result, only the total score of stigma entered the regression model $(p=0.003<0.05)$. It is thus learned that stigma would affect the intentions to seek help (See Table 10).

\subsubsection{Factors Affecting Recourse to Help}

Of the 77 teenagers participating in the survey, 44 said they would seek help from a mental health or medical professional/counselor; 17 would seek help from classmates/peers, 7 would seek help from family members, 3 would seek help from teachers/school doctors/other school staff, and 6 would seek help from other groups or not. Their average scores of depression literacy were 11.27 points, 10.65 points, 10.29 points, 11.00 points and 9.00 points, respectively. Through the One-way ANOVA, there is no significant difference among the groups $(p>0.05)$

Table 9. Analysis on correlation between stigma and depression literacy.

\begin{tabular}{cccc}
\hline & & Total Score of Stigma & Depression Literacy \\
\hline \multirow{2}{*}{ Total Score of Stigma } & Pearson correlation & 1 & 0.338 \\
& Sig. (2-tailed) & 77 & 0.003 \\
& Number of cases & 77 & 1 \\
Depression Literacy & Pearson correlation & 0.338 & 77 \\
& Sig. (2-tailed) & 0.003 & 77 \\
\hline
\end{tabular}

Table 10. Logistic regression analysis on factors affecting the teenagers' intentions to seek help.

\begin{tabular}{cccccc}
\hline Variable & $\begin{array}{c}\text { Log } \\
\text { likelihood }\end{array}$ & $\begin{array}{c}\text { Change in - 2 log } \\
\text { likelihood }\end{array}$ & df & $\begin{array}{c}\text { Sig. Of the } \\
\text { Change }\end{array}$ \\
\hline Step 1 & Total score of stigma & -19.156 & 8.628 & 1 & 0.003 \\
\hline
\end{tabular}




\subsubsection{Factors Affecting Possible Obstacles for Help Seeking}

Of the 77 teenagers, 44 had the obstacle in stigma; 14 had the obstacle in Depression Literacy; 11 had the obstacle in social resources and 8 had no obstacle. Their average scores of stigma were 23.09 points, 23.64 points, 23.64 points, and 28.25 points, respectively; and their average scores of depression literacy were 10.75 points, 10.79 points, 11.55 points and 10.63 points, respectively. The One-way ANOVA was used to compare the stigma scores of teenagers with different obstacles for help seeking. It was found that the stigma of teenagers with no obstacle for help seeking was significantly lower than that of teenagers with obstacles in stigma, Depression Literacy and social resource $(p<0.05)$. Then, the One-way ANOVA was used to compare the score of depression literacy of teenagers with different obstacles for help seeking. It was found that there was no significant difference in depression literacy among teenagers with different obstacles for help seeking $(p>0.05)$ (See Table 11).

\section{Discussion}

\subsection{Depression Literacy and Its Possible Attributions}

\subsubsection{General Situation of Depression Literacy}

The average score of depression literacy of teenagers participating in the survey is 10.86 , lower than the average score of the control group American teenagers in the survey by Swartz. It is thus clear that there is still a gap in depression literacy between teenagers in first and second tiered cities in China and the developed countries, which may be related to the fact that American teenagers have been more exposed to related publicity while Chinese teenagers have been less

Table 11. Multiple comparisons among stigma scores of teenagers with different obstacles for help seeking.

\begin{tabular}{|c|c|c|c|c|c|c|}
\hline \multirow{2}{*}{$\begin{array}{l}\text { (I) Obstacles } \\
\text { for Help } \\
\text { Seeking }\end{array}$} & \multirow{2}{*}{$\begin{array}{c}\text { (J) Obstacles } \\
\text { for Help Seeking }\end{array}$} & \multirow{2}{*}{$\begin{array}{c}\text { Mean } \\
\text { difference } \\
(\mathrm{I}-\mathrm{J})\end{array}$} & \multirow{2}{*}{$\begin{array}{l}\text { Standard } \\
\text { Error }\end{array}$} & \multirow{2}{*}{ Sig. } & \multicolumn{2}{|c|}{$\begin{array}{c}\text { 95\% Confidence Interval } \\
\text { of the Difference }\end{array}$} \\
\hline & & & & & Lower & Upper \\
\hline \multirow{3}{*}{ Stigma } & Depression Literacy & -0.552 & 1.486 & 0.711 & -3.51 & 2.41 \\
\hline & Social Resources & -0.545 & 1.632 & 0.739 & -3.80 & 2.71 \\
\hline & No obstacle & $-5.159^{*}$ & 1.861 & 0.007 & -8.87 & -1.45 \\
\hline \multirow{3}{*}{$\begin{array}{l}\text { Depression } \\
\text { Literacy }\end{array}$} & Stigma & 0.552 & 1.486 & 0.711 & -2.41 & 3.51 \\
\hline & Social Resources & 0.006 & 1.951 & 0.997 & -3.88 & 3.89 \\
\hline & No obstacle & $-4.607^{\star}$ & 2.146 & 0.035 & -8.88 & -0.33 \\
\hline \multirow{3}{*}{ Social Resources } & Stigma & 0.545 & 1.632 & 0.739 & -2.71 & 3.80 \\
\hline & Depression Literacy & -0.006 & 1.951 & 0.997 & -3.89 & 3.88 \\
\hline & No obstacle & $-4.614^{*}$ & 2.249 & 0.044 & -9.10 & -0.13 \\
\hline \multirow{3}{*}{ No obstacle } & Stigma & $5.159^{*}$ & 1.861 & 0.007 & 1.45 & 8.87 \\
\hline & Depression Literacy & $4.607^{*}$ & 2.146 & 0.035 & 0.33 & 8.88 \\
\hline & Social Resources & $4.614^{*}$ & 2.249 & 0.044 & 0.13 & 9.10 \\
\hline
\end{tabular}


exposed. Through the last three items with relatively low accuracy "People who experiences major stressors, such as parents' divorce, always suffer from depression", "Bipolar affective disorder is more common than major depression" and "Major depression is a treatable disease", we can see that the teenagers in first and second tiered cities in China still have a stereotype about the severity of depression and have little idea of the treatment of depression.

\subsubsection{Possible Attributions of Depression Literacy}

1) Demographic Factors

Different from Arafat et al.'s (2019) findings in Bangladesh, it was found in this study that teens who thought they might have had depression-like symptoms had higher levels of depression awareness that there was no significant difference in depression literacy between male and female, but age has a significant impact on the teenagers' depression literacy. The teenagers aged 15 - 19 have a higher depression literacy, which may have something to do with the fact that teenagers aged 15 - 19 are more stressed due to schoolwork, adolescence and other reasons, and are more willing to search for relevant information.

\section{2) Depression-related Experience}

It was found in this study that teens who said they might have had depression-like symptoms had higher depression literacy. They are more likely to actively collect relevant information to increase their understanding of mental state. And teenagers who said their family members might have had depression-like symptoms did not have significantly higher depression literacy than those who said their family members might not have had. This shows that although teenagers' own condition may make them actively search for relevant information, they will not increase their understanding of depression because of the conditions of people around them.

\section{3) Information Sources}

It was found in the survey that the main information sources about depression of teenagers were the Internet and peers, and teenagers whose information sources included the Internet and peers had no higher depression literacy. This shows that the network information is numerous and complex, from which teenagers can extract less useful information. However, as many teenagers learn relevant knowledge from the Internet, relevant workers in the future should pay attention to the publicity of depression-related knowledge on the Internet. At the same time, among the sources of depression-related information of teenagers, school teachers and relevant professionals account for a relatively low proportion, and there is no significant difference in depression literacy between teenagers whose sources include these two and those who do not receive information from these two sources. This suggests that schools and professionals publicize little depression-related information, and adolescents get little useful information about it. As an authoritative information source for teenagers, schools and relevant professionals can increase the publicity of depression, thus increasing the teenagers' depression literacy. 


\subsection{Depression Stigma and Its Possible Attributions}

It was found in this study that demographic factors and depression-related experiences had no significant effect on teenagers' perceived stigma of depression. This is not consistent with the conclusions of Jorm et al., which may be caused by the small sample size. Moreover, this paper adopts the self-rated depression-related experience of teenagers, which lacks professional diagnosis, and this may also affect the attribution of depression-related experience that affects perceived stigma.

However, it was found in this survey that there was a negative correlation between depression literacy and perceived stigma of teenagers. The higher the depression literacy of teenagers is, the lower the perceived stigma is. This is consistent with the research conclusions of Luo Jianjun, and those of Jorm et al.

\subsection{Intentions to Seek Help and Its Possible Attributions}

Most of the 77 teenagers participating in the survey said they would seek help if they had depression-like symptoms. This shows that teenagers have a certain awareness of seeking help. At the same time, most teenagers said that there were still relevant factors that might prevent them from seeking help, and stigma was still the main factor. However, teenagers who said they had no obstacle for help seeking had a significantly lower perceived stigma of depression than other teenagers. This suggests that reducing teenagers' perceived stigma may encourage them to seek help more actively.

In this survey, only stigma was screened out as the influencing factor of the willingness to seek help, and the influences of gender, age, depression-related experiences and depression-related knowledge on the intentions to seek help were not found. This may be caused by the small sample size, and the factors influencing teenagers' intentions to seek help remain to be further investigated. Considering the correlation between depression literacy and perceived stigma, the results of this study can be interpreted to be that the depression literacy affects perceived stigma of depression, and that perceived stigma further affects teenagers' intentions to seek help.

\section{Conclusion}

This study explores the relations between teenagers' depression literacy, perceived stigma of depression, and teenagers' intention to recourse to professional help. By surveying 77 Chinese teenagers, we found that teenagers aged 15 - 19 who reported to have similar symptom of depression had higher score in depression literacy, that perceived stigma and depression literacy are negatively correlated, and that perceived stigma has influence on teenagers' willingness to seek for help.

This study adopted the concept of depression literacy as a counterpart of mental health literacy and investigated the influence of depression literacy on stigma of depression. To estimate the depression literacy of Chinese teenagers, 
we introduced translated version of the Adolescent Depression Knowledge Questionnaire (ADKQ) to Chinese subjects, providing a new measurement of depression literacy to the study of teenage depression in China. Our results indicate that Chinese teenagers' depression literacy is relatively low, which is negatively correlated with stigma of depression, and stigma of depression influences teenagers' intention to seek for help.

The fact that stigma remained a major obstacle for help seeking points to the necessity of reducing perceived stigma. Since depression literacy is negatively correlated with stigma, it is imperative to improve teenagers' depression literacy. One possible means to increase depression literacy is to provide accurate and valid information about depression, since internet is shown in this study to be the main source of information for teenagers in China. Another possibility is to expand the role of schools in publicizing knowledge of depression, for only $29 \%$ of teenagers learn about depression from schools, even though schools are an authoritative source of information for them.

Due to the research design of the study, no causal relationship can be drawn from the study. To understand whether improving depression literacy can reduce Chinese teenagers' stigma and increase willingness to seek for help, longitudinal and experimental studies are needed. And generalizability is limited due to voluntary response. ADKQ may not be a suitable measurement of Chinese teenagers' depression literacy due to cultural differences between China and the United States, and wording of the translated questionnaire may decrease the validity of the translated version of ADKQ. Further studies could be done to investigate the effectiveness of ADKQ in measuring Chinese teenagers' depression literacy. In addition, there may be other factors that have influence on teenagers' stigma that were not measured in this study.

\section{Acknowledgements}

We appreciate the effort of other members of Yuanzhi team, Wang Chujun, Wen Qing, and Tan Yuxuan, in the design of the study and collection of data. We would also like to express our special thanks to Ms. Li Lin and Ms. Zhao Xinyi, who offered us immense help in research design and data analysis.

\section{Conflicts of Interest}

The author declares no conflicts of interest regarding the publication of this paper.

\section{References}

Arafat, S., Mamun, M., \& Uddin, M. (2019). Depression Literacy among First-Year University Students: A Cross-Sectional Study in Bangladesh. Global Psychiatry, 2, 31-36. https://doi.org/10.2478/gp-2019-0002

Guo, Q. F., \& Zhang, H. Y. (2008). A Study on Emotional Experience of Patients with Depression. Chinese Journal of Nursing, No. 11, 965-968. 
Hart, S. R. et al. (2014). Achieving Depression Literacy: The Adolescent Depression Knowledge Questionnaire (ADKQ). School Mental Health, 6, 213-223. https://doi.org/10.1007/s12310-014-9120-1

Jorm, A., \& Wright, A. (2008). Influences on Young People's Stigmatising Attitudes towards Peers with Mental Disorders: National Survey of Young Australians and Their Parents. British Journal of Psychiatry, 192, 144-149.

https://doi.org/10.1192/bjp.bp.107.039404

Liu, B. H., Sun, Z. W., Sun, W., \& Chang, C. (2013). Application of the Chinese version of the Depression Stigma Scale in the People Aged 15 - 24 in Beijing. Chinese Journal of Health Education, 29, 116-119.

Luo, J. J. (2012). A Study on the Intentions of Rural Residents in Liuyang City to Seek Professional Psychological Help and Its Influencing Factors. Changsha: Central South University.

Ma, R. N. (2016). A Study on the Intervention of Social Work in Adolescent Depression. Beijing: Capital University of Economics and Business.

Su, J. H. (2015). Investigation of Junior School Students' Mental Health Condition and Help-Seeking Intention in Guangdong, Huaiji. The 13th National Conference on Psychiatry, Chinese Medical Association, 25, 16-17.

Sun, S. W., Chang, C., Sun, W., \& Liu, B. H. (2013). Perceived Stigma of Depression and Help-Seeking Intentions of Teenagers. Chinese Journal of School Health, 34, 528-530+533.

Swartz, K. et.al. (2007). The Effectiveness of a School-Based Adolescent Depression Education Program. Health Education \& Behavior, 37, 11-22.

https://doi.org/10.1177/1090198107303313

Wahl, O. F. (1999). Mental Health Consumers' Experiences of Stigma. Schizophrenia Bullet, 25, 467-478. https://doi.org/10.1093/oxfordjournals.schbul.a033394

World Health Organization (2017). Depression and Other Common Mental Disorders (pp. 19-20).

Xu, G. M., Yin, H. F., Yang, G. F., \& Tian, H. J. (2014). A Survey on Stigma of Mental Illness of Community Population in Tianjin. Chinese Mental Health Journal, 28, 97-103.

Ye, D. J. (2008). Adolescent Depression and Intervention of Social Work. Chinese Journal of School Doctor, No. 5, 595-596.

Zhou, Y., Yang, B. X., Wang, Xi. Q., Chen, W. C., Liu, X. J., Liu, L. Z., \& Liu, Z. C. (2019). A Survey on Depression Stigma of Urban Residents in Wuhan City and Analysis of Influencing Factors. Neural Injury and Functional Reconstruction, 14, 299-302. 